\title{
ENDOZOOCHOROUS DISPERSAL OF AQUATIC PLANTS: DOES SEED GUT PASSAGE AFFECT PLANT PERFORMANCE? ${ }^{1}$
}

\author{
Jordi Figuerola, ${ }^{2}$ Luis SANTAMARÍA, ${ }^{3,5}$ Andy J. GReEn, ${ }^{2}$ \\ Isabel LuQue, ${ }^{2}$ RaQuel Alvarez, ${ }^{4}$ And Iris Charalambidou ${ }^{3}$
}

\begin{abstract}
${ }^{2}$ Department of Applied Biology, Estación Biológica de Doñana, CSIC, Avda. María Luisa s/n. E-41013 Sevilla, Spain; ${ }^{3}$ Netherlands Institute of Ecology, Centre for Limnology, PO Box 1299, 3600 BG Maarssen, The Netherlands; and ${ }^{4}$ Biology and Ethology Unit, Facultad de Veterinaria, University of Extremadura, 10071 Cáceres, Spain
\end{abstract}

\begin{abstract}
The ingestion of seeds by vertebrates can affect the germinability and/or germination rate of seeds. It is, however, unclear if an earlier germination as a result of ingestion affects later plant performance. For sago pondweed, Potamogeton pectinatus, the effects of seed ingestion by ducks on both germinability and germination rate have been previously reported from laboratory experiments. We performed an experiment to determine the effects of seed ingestion by ducks on germination, seedling survival, plant growth and asexual multiplication. Both at the start and end of the winter, seeds were fed to three captive shovelers (Anas clypeata) and planted outdoors in water-filled containers. Plant biomass and its allocation to vegetative parts (shoot and roots), tubers, and seeds were determined in autumn. More duck-ingested seeds than control (uningested) seeds germinated in early winter, but this difference disappeared for seeds planted in late winter, when the treatments were first stratified for 3 mo. None of the variables for measuring seedling survival and plant performance varied between treatments. Under our experimental conditions (no herbivory or competition), ingestion by ducks in early winter resulted in increased performance for seeds surviving gut passage due to enhanced seed germinability, without other costs or benefits for the seedlings.
\end{abstract}

Key words: germination phenology; germination rate; plant performance; seed dispersal; seedling establishment.

The effects of ingestion by vertebrates on the capacity of seeds to germinate have been studied in many systems, and effects on the germinability of seeds or the rate of germination have often been reported (Traveset, 1998; Traveset and Verdú, 2002). Although changes in these parameters have generally been assumed to have an adaptive value for the plants, this may not necessarily be true for two reasons. First, delayed germination of non-ingested seeds is likely to represent a defense cost against digestion by seed dispersers or predators (e.g., through the acquisition of thicker or less permeable seed coats), rather than an adaptive response promoting (early) germination of endozoochorously dispersed seeds. Second, both increases and decreases in germination rate can be interpreted as adaptive responses of plants to adjust their germination patterns to habitat characteristics (e.g., Barnea et al., 1991). Under field conditions, seedlings are exposed to different selective pressures. Although early germination can reduce the levels of intra- and interspecific competition (Garwood, 1983; Loiselle, 1990), early-growing seedlings can also be exposed to harsher climatic conditions (as suggested by Janzen, 1981), to increased damage by pathogens (e.g., fungus infection, Traveset, 1990) or to predation by herbivores (Figuerola and Green,

\footnotetext{
${ }^{1}$ Manuscript received 11 May 2004; revision accepted 8 December 2004. The authors thanks Thijs de Boer, Eva Casado, Gema García, Judit Hidalgo, Matati Perez, and Cristina Belén Sánchez for assistance during the experiment. Comments by Anna Traveset improved an earlier version of the manuscript. The Junta de Andalucía and Pesquerías Isla Mayor S.A. gave us access to Veta la Palma to collect seeds. This study was supported by funding from the European Union Project LAKES (Long distance dispersal of aquatic key species) (ENV4-CT97-0585). Luis Santamaría was supported by a grant awarded by the Schure-Beijerinck-Poppings Fonds (Royal Dutch Academy of Arts and Sciences, KNAW).

${ }^{2}$ Author for correspondence (e-mail: jordi@ebd.csic.es)

${ }^{5}$ Present address: IMEDEA (CSIC-UIB), c/ Miguel Marquès 21, E-07190 Esporles, Spain.
}

2004). Consequently, the final outcome of seed ingestion by vertebrates is not clear and most likely depends on both the characteristics of the specific plant-disperser system and the local conditions.

The direct or indirect effects of ingestion by vertebrates may exceed the period of seed germination and have long-term impacts on plant performance. First, effects of gut passage on germination phenology are likely to affect the length of time available for growth and reproduction and thus may translate into effects on plant size, asexual perennation, and sexual fecundity. As far as we know, ours is the first study to address this question. Second, seed ingestion may select for certain seed characteristics that enhance survival of gut passage (for example, smaller seeds or those with harder seed coats, Agami and Waisel, 1988; Traveset and Verdú, 2002). For example, larger seeds may be more likely to be damaged during gut passage (Figuerola and Green, 2002) and represent a larger reward for vertebrate and invertebrate seed predators (Hulme, 1993; Van der Wall, 1994; Moegenburg, 1996; Alexander et al., 2001); however, seedlings originating from larger seeds often have increased survival and establishment (Schaal, 1980; Foster, 1986; Susko and Lovett-Doust, 2000) and competitive ability (Houssard and Escarré, 1991; Turnbull et al., 1999).

In the case of sago pondweed (Potamogeton pectinatus Linnaeus), we have previously reported the effects of seed ingestion by ducks on seed survival, germinability, and germination rate in laboratory experiments (Santamaría et al., 2002). In this paper, we report the effects of experimental simulation of vertebrate ingestion of $P$. pectinatus seeds under controlled field conditions, which excluded the effects of herbivory and intraor interspecific competition, on short-term (germinability) and long-term (growth and reproduction) plant performance. Ingestion was simulated at two different times, at the beginning and end of winter, to separate the direct effects of gut passage 
on seedling growth and survival from the indirect effects mediated by changes in seed germination phenology. We monitored the fate of the resulting seedlings until the end of the growing season to detail the impact of ingestion on seedling development. In agreement with previous work analyzing the performance in this species (Santamaría et al., 2003), we used two determinants of asexual population growth rate (the production of asexual propagules and the number of ramets) instead of fecundity as short-term surrogates of plant performance (see also Crone, 2001). We focus on the performance of seeds surviving ingestion by ducks. Although a variable proportion of the seeds consumed by ducks are destroyed during gut passage (Figuerola et al., 2002), in this paper, we do not consider the costs of seed ingestion to the mother plant (but see Santamaría et al., 2002).

\section{MATERIALS AND METHODS}

Achenes of Potamogeton pectinatus (hereafter referred to as "seeds") were collected in Veta la Palma, Doñana Natural Park (36 $57^{\prime} \mathrm{N}, 6^{\circ} 14^{\prime}$ W) in October 2000, separated from debris, and kept moist, at $5 \pm 11^{\circ} \mathrm{C}$ and in darkness until further use. All seeds were mixed together, then divided into 24 batches of 50 seeds, which were then randomly assigned to the different treatments (a factorial combination of two treatments, control vs. ingested, and two experimental runs, early vs. late winter; three batches each). Seeds from the ingested treatment were fed to three shovelers (Anas clypeata) kept in captivity ( 150 seeds each). To facilitate force-feeding, the seeds were mixed with food pellets (Anseres 3, Kasper Faunafood, Woerden, The Netherlands) soaked in water and formed into oblong pills. Droppings produced during the $24 \mathrm{~h}$ after feeding were collected and sieved to separate undamaged seeds. The seeds recovered intact from the feces were subsampled, and 25 from each duck were used in the early winter experiment. In the late winter experiment, no intact seeds were recovered from one of the ducks, and a sample of 30 seeds ingested by each of the other two ducks was planted. Control and ingested seeds were stored wet in the refrigerator for up to $6 \mathrm{~d}$ until the day before planting. A random subsample of the 150 control seeds originally selected for each experimental run was planted, in order to measure the germination and development of a comparable number of duck-ingested and control seeds. We did not depulp the control seeds.

Each seed was planted in a separate plastic pot $(1 \mathrm{~L}$ volume, $11.5 \mathrm{~cm}$ upper diameter), filled with a mixture of potting clay and sand ( $1: 3$ by dry weight) covered with $1-2 \mathrm{~cm}$ of washed aquarium sand. Pots were randomly distributed inside five (three for the early winter run, two for the late winter run) separate containers $(550 \mathrm{~L}$ volume and $110 \mathrm{~cm}$ length $\times 95 \mathrm{~cm}$ width $\times 65$ $\mathrm{cm}$ height, with 60 pots per container). Each container received ingested seeds and a corresponding number of control seeds (hence, we nested the ingestion vs. control treatment within a random factor "tank" and also incorporated the random factor "duck individual"). The containers were situated outside the Bolin Laboratory in Doñana National Park and filled with groundwater from a local aquifer that discharges into the Doñana marshes. In the early winter experiment, we used 101 control and 75 experimental pots (one seed per pot) and in the late winter experiment, 60 pots for each treatment. Each container was covered with $35 \%$ neutral density shading net to reproduce shading conditions typical of shallow lakes inhabited by $P$. pectinatus and to limit the amount of debris and insects falling into the water.

Seeds were sown on 10 November 2000 (early winter run) and 29 March 2001 (late winter run), and the resulting plants were grown until 1 October 2001. We used the late-winter ingestion run to evaluate any costs or benefits for the plants after germinating in early (as opposed to late) winter, because early germination may result from seed ingestion in autumn, and to separate experimentally this effect from the potential costs of passage through the duck gut. Germination was checked at monthly intervals. Upon harvest, sediment was washed off using pressurized water and plants and tubers collected on a 2-mm sieve. We first measured the length of the longest shoot and the number of ramets per plant. Aboveground (shoots) and belowground (roots + rhi-

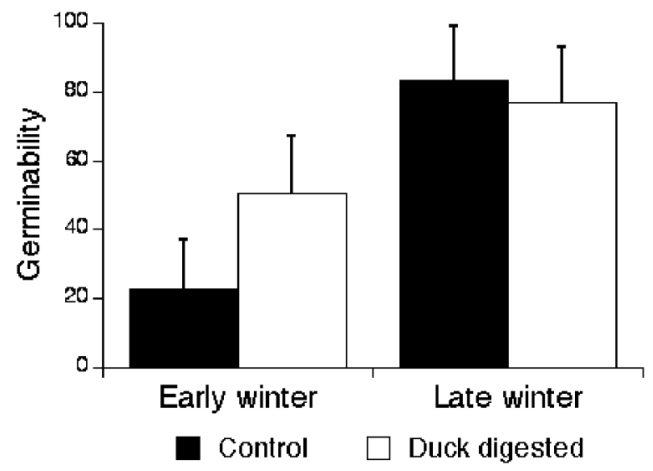

Fig. 1. Proportion of seeds germinating $(+\mathrm{SE})$ for fennel pondweed seeds (Potamogeton pectinatus) planted in early and late winter.

zomes) parts were then separated and their biomass measured (dry weight, after drying at $60^{\circ} \mathrm{C}$ for at least $48 \mathrm{~h}$ ). Tubers were weighed individually, and the number of tubers, inflorescences and seeds counted. Plant biomass was determined as the sum of the dry mass of shoots, roots + rhizomes, flowers, seeds, and tubers.

Statistical analysis-Differences in germinability between duck-ingested and control seeds were tested with a generalized linear mixed model. Models were fitted using restricted maximum likelihood with binomial errors for presence/absence response variables and normal errors for continuous response variables. A two-level, fixed-effect factor (duck ingested vs. control seeds) and one random factor (water tank) were included as independent variables in the model. Each experiment (ingestion at early or late winter) was analyzed independently because germination and growth took place in different tanks, so we were unable to separate the effects due to time of planting from those due to tanks. To produce normal distributions, the square root of the number of shoots and the logarithm of shoot length were used in the analyses. Differences in shoot-to-root allocation were estimated as the residuals of a reduced major axis (RMA) regression between shoot mass and roots + rhizomes mass. RMA instead of ordinary least squares regression (OLS) was used because both the dependent and independent variables were measured with error (see Green, 2001 for a discussion of the use of model II residuals in ecology). Differences between treatments in the number of asexual propagules (subterranean tubers) and inflorescences were assessed using Wilcoxon signed-rank tests, because data were not normally distributed and the reduced sample size did not allow for control of the effects of replicate tanks. Differences in survival between both experiments were tested with Yates corrected chi-squared tests.

\section{RESULTS}

Effects of ingestion on germinability-Germinability was significantly greater for duck ingested seeds than for controls in the early winter run $\left(\chi^{2}=15.21,1 \mathrm{df}, P<0.0001\right)$, but no significant differences were detected in the late winter run $\left(\chi^{2}=0.84,1 \mathrm{df}, P=0.36\right.$, Fig. 1$)$. In each run, the great majority of seeds that germinated did so within the month following planting (95\% for early winter and $100 \%$ for late winter). Mortality was low, but significantly higher in early $(8 \%)$ than late winter $\left(0 \%, \chi^{2}=5.80,1 \mathrm{df}, P=0.02\right)$. The five plants that died were equally distributed among treatments ( 3 controls and 2 duck ingested seeds, $\chi^{2}=0.71,1 \mathrm{df}, P=$ $0.40)$.

Effects of ingestion on development-No significant differences between duck-ingestion treatments were found in the number of ramets per plant (early winter, $F_{1,49}=0.67, P=$ 0.42 ; late winter, $F_{1,93}=0.09, P=0.76$; Table 1 ), maximum 
TABLE 1. Characteristics of plants originating from duck ingested and control seeds. Mean \pm SE and sample size (in parentheses) are reported for original data.

\begin{tabular}{|c|c|c|c|c|}
\hline \multirow[b]{2}{*}{ Plant characteristics } & \multicolumn{2}{|c|}{ Early winter } & \multicolumn{2}{|c|}{ Late winter } \\
\hline & Control & Duck ingested & Control & Duck ingested \\
\hline Shoot number & $18.5 \pm 1.1$ & $17.2 \pm 0.9$ & $19.6 \pm 1.0$ & $20.5 \pm 1.0$ \\
\hline Max. shoot length $(\mathrm{cm})$ & $57.4 \pm 2.5$ & $54.3 \pm 1.8$ & $56.1 \pm 1.0$ & $54.7 \pm 1.1$ \\
\hline Internode length $(\mathrm{cm})$ & $40.1 \pm 2.9$ & $43.4 \pm 2.3$ & $41.8 \pm 1.6$ & $43.7 \pm 1.5$ \\
\hline Shoot mass (g DW) & $0.92 \pm 0.08$ & $0.85 \pm 0.05$ & $0.93 \pm 0.05(50)$ & $1.00 \pm 0.06(46)$ \\
\hline Roots + rizome mass (g DW) & $0.48 \pm 0.05$ & $0.44 \pm 0.03$ & $0.41 \pm 0.02(50)$ & $0.44 \pm 0.02(46)$ \\
\hline Plant mass (g DW) & $1.40 \pm 0.12$ & $1.28 \pm 0.08(35)$ & $1.34 \pm 0.07(50)$ & $1.46 \pm 0.08(46)$ \\
\hline Number flowers + seeds & $2.0 \pm 1.0$ & $1.7 \pm 0.7$ & $3.2 \pm 1.0$ & $4.1 \pm 3.0$ \\
\hline Number of tubers & $2(1)$ & $1.3 \pm 0.2 \quad(7)$ & $1.3 \pm 0.3$ & $1.3 \pm 0.3 \quad(6)$ \\
\hline Germinating (\%) & $21.8(101)$ & $50.7(75)$ & $83.3(60)$ & $76.7(60)$ \\
\hline Flowering (\%) & $16.7(18)$ & $8.3(36)$ & $10.0(50)$ & $15.2(46)$ \\
\hline Tuberizing (\%) & $5.6(18)$ & $19.4(36)$ & $6.0(50)$ & $13.0(46)$ \\
\hline
\end{tabular}

shoot length (early winter, $F_{1,49}=3.77, P=0.06$; late winter, $F_{1,93}=0.91, P=0.34$ ), the length of the first internode (early winter, $F_{1,49}=0.34, P=0.56$; late winter, $F_{1,93}=0.97, P=$ 0.33 ), shoot mass (early winter, $F_{1,49}=0.10, P=0.75$; late winter, $\left.F_{1,93}=0.05, P=0.83\right)$, the mass of the roots + rhizomes (early winter, $F_{1,49}=0.16, P=0.69$; late winter, $F_{1,93}$ $=0.46, P=0.50$ ), total biomass (early winter, $F_{1,49}=0.11$, $P=0.74$; late winter, $F_{1,93}=0.38, P=0.54$ ) or shoot-to-root allocation (early winter, $F_{1,49}=0.02, P=0.89$; late winter, $\left.F_{1,93}=0.35, P=0.56\right)$.

Effects of ingestion on sexual and asexual reproductionNo significant differences between duck-ingestion and control treatments were found in the number of tubers produced per plant (early winter, $Z=1.03, P=0.30$; late winter, $Z=0.18$, $P=0.86$; Table 1$)$, the proportion of plants producing tubers (early winter, $\chi^{2}=0.01,1 \mathrm{df}, P=0.96$; late winter, $\chi^{2}=$ $1.39,1 \mathrm{df}, P=0.24)$, the number of inflorescences per plant (early winter, $Z=0.00, P=1.00$; late winter, $Z=1.31, P$ $=0.19$ ), the proportion of plants producing flowers (early winter, $\chi^{2}=0.48,1 \mathrm{df}, P=0.49$; late winter, $\chi^{2}=0.16,1 \mathrm{df}, P$ $=0.69$ ), or the proportion of plants producing reproductive organs (sexual + asexual; early winter, $\chi^{2}=0.38,1 \mathrm{df}, P=$ 0.54 ; late winter, $\chi^{2}=0.54,1 \mathrm{df}, P=0.46$ ).

\section{DISCUSSION}

The ingestion of seeds by vertebrates is an important process affecting the distribution, structure, and composition of plant communities (see Fenner, 2000). In our experiment, ingestion by ducks had a positive, short-term effect on the germinability of seeds surviving predation. However, such an effect was apparent only if seeds were ingested and planted in early winter, not for seeds ingested in late winter. Gut passage can break the dormancy of pondweed seeds (see also Lohammar, 1954; Smits et al., 1989; Santamaría et al., 2002) and is thus equivalent to the effects of winter stratification (simulated here through a 3 -mo storage at $5^{\circ} \mathrm{C}$ ). The possible interaction between gut passage and other dormancy-breaking processes (such as stratification or drought, Probert, 2000; Murdoch and Ellis, 2000) can explain the great diversity of results obtained when analyzing the effects of gut passage on seed germination patterns (see Traveset, 1998; Traveset and Verdú, 2002).

It is important to note, however, that the population chosen for our study does not naturally undergo periods of winter stratification as severe as those imposed by our seed storage conditions previous to the second (late-winter) experimental run. This is clearly indicated by the lower germinability of the control seeds from early winter (which were exposed to natural conditions in the field) as compared with late winter controls, and by the high germination rate of control seeds from early winter (of the seeds that germinated, $95 \%$ of early winter and $100 \%$ of late winter seeds germinated within a month of planting). If winter stratification under field conditions contributed to faster or enhanced germination, it would have resulted in either a slower germination rate of seeds planted in early winter (i.e., in progressive germination through the whole winter) or in a second peak of germination in early spring. Seed storage at low temperature was necessary to prevent seed germination before the late-winter experiment was carried out, but its use means that the germination rates in late winter are not representative of actual field conditions (mean daily field air temperature exceeded $11^{\circ} \mathrm{C}$ for November through March, and control seeds were stored during this time at $5^{\circ} \mathrm{C}$ ).

If winter temperatures in the field are not low enough to ensure dormancy breakage via seed stratification, enhanced seed germination following gut passage represents a genuine enhancement of plant performance. Even if dormant seeds enter the seed bank and suffer insignificant mortality there, a delay in establishment of at least one growing season is likely to represent a serious handicap for such dormant seeds, particularly in populations likely to be exposed to high predation of seeds by waterfowl (e.g., Van Eerden, 1990; Green et al., 2002). Although we lack quantitative information on the rates of herbivory and seed predation by ducks on Potamogeton pectinatus in southern Spain, it is important to note that seed ingestion can take place at any time between fruit production in July through August and late winter (e.g., seeds of Ruppia and other marsh plants were consumed by ducks all winter, and in some cases, their presence in duck feces was higher at the end of the winter than in autumn; Figuerola et al., 2002, 2003). Perennation of plants through tubers, which have a higher competitive ability than seeds owing to their higher germinability and much larger reserve storage (Van Wijk, 1989; Spencer and Ksander, 1995) could also enhance the fitness advantage of early germinating seeds. However, seed banks represent an insurance against habitat instability (Thompson, 2000). Consequently, all aspects of habitat stability and seed bank dynamics should be considered before concluding that germination after duck digestion is a better option than dormancy.

In contrast with the important effect of duck ingestion on early-winter germinability, we did not find any subsequent ef- 
fect on pondweed performance. Plants grown from ingested and non-ingested seeds showed comparable seedling survival, dry-mass accumulation, shoot-to-root allocation, clonal multiplication, and sexual reproduction by the time of harvest in October. As far as we know, ours is the first study to address the effects of ingestion on such measures of plant performance. Our previous work with seed dispersal by waterfowl in Doñana suggests that most dispersal probably occurs at a local scale (Figuerola et al., 2002, 2003), with little room for local adaptation to limit dispersal. However, some seeds may be dispersed over larger distances, where the adaptation of clones to local conditions can limit the establishment of new immigrants (Santamaría et al., 2003). We must thus conclude that, under the controlled conditions of our experiment (i.e., in the absence of herbivory pressure and intra- or interspecific competition), enhancement of germinability represents the only significant effect of gut passage on the long-term performance of ingested seeds. Further research is required to establish if this is the case for other plants dispersed by vertebrates.

\section{LITERATURE CITED}

Agami, M., And Y. Waisel. 1988. The role of fish in distribution and germination of seeds of the submerged macrophytes Najas marina L. and Ruppia maritima L. Oecologia 76: 83-88.

Alexander, H. M., C. L. Cummings, L. Kahn, And A. A. Snow. 2001. Seed size variation and predation of seeds produced by wild and cropwild sunflowers. American Journal of Botany 88: 623-627.

Barnea, A., Y. Yom-Tov, AND J. Friedman. 1991. Does ingestion by birds affect seed germination? Functional Ecology 5: 394-402.

Crone, E. E. 2001. Is survivorship a better fitness surrogate than fecundity? Evolution 55: 2611-2614.

FEnNER, M. 2000. Seeds: the ecology of regeneration in plant communities. CABI Publishing, Wallingford, UK.

Figuerola, J., AND A. J. GREen. 2002. Dispersal of aquatic organisms by waterbirds: a review of past research and priorities for future studies. Freshwater Biology 47: 483-494.

Figuerola, J., AND A. J. GReEN. 2004. Effects of seed ingestion by birds and herbivory on seedling establishment: a field experiment with wigeongrass Ruppia maritima. Plant Ecology 173: 33-38.

Figuerola, J., A. J. Green, AND L. Santamaría. 2002. Comparative potential for seed dispersal in waterfowl wintering in southern Spain: quantitative and qualitative aspects. Journal of Ecology 90: 989-1001.

Figuerola, J., A. J. Green, And L. Santamaría. 2003. Passive internal transport of aquatic organisms by waterfowl in Doñana, south-west Spain. Global Ecology and Biogeography 12: 427-436.

FosTER, S. A. 1986. On the adaptive value of large seeds for tropical moist forest trees: a review and synthesis. Botanical Review 52: 260-299.

GARWOOD, N. C. 1983. Seed germination in a seasonal tropical forest in Panama: a community study. Ecological Monographs 53: 159-181.

Green, A. J. 2001. Mass/length residuals: measures of body condition or generators of spurius results? Ecology 82: 1473-1483.

Green, A. J., J. Figuerola, And M. I. SÁnchez. 2002. Implications of waterbird ecology for the dispersal of aquatic organisms. Acta Oecologica 23: 177-189.

Houssard, C., AND J. EsCARRÉ. 1991. The effects of seed weight on growth and competitive ability of Rumex acetosella from two successional oldfields. Oecologia 86: 236-242.
Hulme, E. 1993. Post dispersal seed predation by small mammals. Symposia of the Zoological Society of London 65: 269-287.

JANZEN, D. H. 1981. Enterolobium cyclocarpum seed passage rate and survival in horses, Costa Rican Pleistocene seed dispersal agents. Ecology 62: 593-601.

Lohammar, A. G. 1954. The effect of digestion on the germination of Potamogeton seeds. Fauna och Flora 1-2: 17-32.

LoISELLE, B. A. 1990. Seeds in droppings of tropical fruit-eating birds: importance of considering seed composition. Oecologia 82: 494-500.

MoegenburG, S. M. 1996. Sabal palmetto seed size: causes of variation, choices of predators, and consequences for seedlings. Oecologia 106: 539-543.

Murdoch, A. J., AND R. H. ElLis. 2000. Dormancy, viability and longevity. In M. Fenner [ed.], Seeds: the ecology of regeneration in plant communities, 183-214. CABI Publishing, Wallingford, UK.

Probert, R. J. 2000. The role of temperature in the regulation of seed dormancy and germination. In M. Fenner [ed.], Seeds: the ecology of regeneration in plant communities, 261-292. CABI Publishing, Wallingford, UK.

Santamaría, L., I. Charalambidou, J. Figuerola, and A. J. Green. 2002. Effect of passage through duck gut on germination of fennel pondweed seeds. Archiv für Hydrobiologie 156: 11-22.

Santamaría, L., J. Figuerola, J. J. Pilon, M. Mjelde, A. J. Green, T. De BoER, R. A. KING, AND R. J. GoRNALl. 2003. Plant performance across latitude: the role of plasticity and local adaptation. Ecology 84: 24542461.

SchaAl, B. A. 1980. Reproductive capacity and seed size in Lupinus texensis. American Journal of Botany 67: 703-709.

Smits, A. J. M., R. Van RuRemonde, and G. Van der Velde. 1989. Seed dispersal of three Nymphaeid macrophytes. Aquatic Botany 35: 167-180.

SPENCER, D. F., AND G. G. KsANDER. 1995. Influence of propagule size, soil fertility, and photoperiod on growth and propagule production by three species of submersed macrophytes. Wetlands 15: 134-140.

Susko, D. J., AND L. LovetT-Doust. 2000. Patterns of seed mass variation and their effects on seedling traits in Alliaria petiolata (Brassicaceae). American Journal of Botany 87: 56-66.

ThOMPSON, K. 2000. The functional ecology of soil seed banks. In M. Fenner [ed.], Seeds: the ecology of regeneration in plant communities, 215-236. CABI Publishing, Wallingford, UK.

Traveset, A. 1990. Post-dispersal predation of Acacia farnesiana seeds by Stator vachelliae (Bruchidae) in Central America. Oecologia 84: 506512.

Traveset, A. 1998. Effect of seed passage through vertebrate frugivores' guts on germination: a review. Perspectives in Plant Ecology, Evolution and Systematics 1: 151-190.

Traveset, A., AND M. Verdú. 2002. A meta-analysis of the effect of gut treatment on seed germination. In D. J. Levey, W. R. Silva, and M. Galetti [eds.], Seed dispersal and frugivory: ecology, evolution and conservation, 339-350. CAB International, Wallingford, UK.

Turnbull, L. A., M. Rees, And M. J. Crawley. 1999. Seed mass and the competition/colonization trade-off: a sowing experiment. Journal of Ecology 87: 899-912.

VAN EERDEN, M. R. 1990. Waterfowl movements in relation to food stocks. In P. R. Evans, J. D. Goss-Custard, and W. G. Hale [eds.], Coastal waders and wildfowl in winter, 84-110. Cambridge University Press, Cambridge, UK.

VAN DER WALL, S. 1994. Removal of wind dispersed pine seeds by groundforaging vertebrates. Oikos 69: 125-132.

VAN WIJK, R. J. 1989. Ecological studies on Potamogeton pectinatus L. III. Reproductive strategies and germination ecology. Aquatic Botany 33: 271-299. 